\title{
Adult malnutrition: simple assessment techniques for use in emergencies
}

\author{
BY ANNA FERRO-LUZZI \\ Istituto Nazionale della Nutrizione, Via Ardeatina 546, 00178 Roma, Italy \\ AND W. P. T. JAMES \\ Rowett Research Institute, Greenburn Road, Bucksburn, Aberdeen AB2 9SB
}

(Received 9 February 1995 - Accepted 3 May 1995)

\begin{abstract}
The recent recognition of the problem of adult malnutrition requires methods for specifying the severity of undernutrition. The measurement of mid upper arm circumference (MUAC) can now be used as a screening method for underweight (normally assessed from the BMI) or as an additional criterion with the BMI to identify the preferential loss of peripheral tissue stores of fat and protein. By analysing and extrapolating anthropometric data from nine detailed adult surveys from Asia, Africa and the Pacific a series of MUAC cut-off points have now been identified to allow the screening of individual adults under extreme conditions, e.g. during famine. Grade 4 malnutrition is now specified for those with a MUAC $<200 \mathrm{~mm}$ for men and $<190 \mathrm{~mm}$ for women since these MUAC values correspond to the loss of fat stores at BMI of $<13$. Food supplementation is clearly needed in these individuals. Extreme wasting (grade 5 malnutrition) corresponds to MUAC values of $<170$ and $<160 \mathrm{~mm}$ for men and women respectively. These adults have extremely low BMI, i.e. about 10 , have lost most, if not all, of their protein stores and are at a high risk of imminent death. These individuals will need immediate special feeding regimens to ensure their survival. The sex-specific MUAC values corresponding to BMI of 16, 13 and 10 can now therefore be used for rapid screening and the choice of remedial action.
\end{abstract}

Malnutrition: Mid upper arm circumference: Famine

Adult malnutrition has recently been recognized as important after many decades of neglect (James et al. 1988). Until now nutritionists have perceived children as not only the most vulnerable group but also that section of society which should be monitored when evaluating the effects of social and economic deprivation. However, this approach ignores the capacity of adults to nurture their children effectively in adverse circumstances and, when the issue is one of inadequate household food security, monitoring children alone disregards the effects of a multiplicity of environmental factors, such as infections, on the nutritional status of a child.

We proposed that adult malnutrition might be assessed by measuring body weight in relation to height by calculating the BMI (James et al. 1988; Ferro-Luzzi et al. 1992), and showed that a series of cut-off points could be applied to grade the severity of underweight in relation to functional impairment (Shetty \& James, 1994). Arm circumference values have also been derived either to substitute for the BMI measurement or to be combined with it as a more selective indicator of the peripheral wasting of muscle and subcutaneous adipose tissue (James et al. 1994). In the present paper we assess whether these techniques can be extended to cope with the demand for simple screening methods when identifying those in desperate need of supplementary feeding in famines or other emergencies. 


\section{METHODS}

The details of nine surveys of Third World communities have been described elsewhere (James et al. 1994). These surveys involved a variety of structured samples from China, India, Ethiopia (three populations), Zimbabwe, Mali, Somalia and Papua New Guinea. In all surveys adults were weighed in minimum clothing on a standard weighing scale; height was measured with a Holtain stadiometer. Arm circumference at the mid-point of the left arm (mid upper arm circumference; MUAC) and triceps skinfold thickness measurements were also taken by standard techniques (Weiner \& Lourie, 1981).

\section{RESULTS}

Table 1 provides an assessment of the prevalence of adult underweight in a number of Third World countries (Shetty \& James, 1994; WHO, 1995). Surprisingly, many parts of Africa, Central and South America have relatively low rates of adult malnutrition when compared with countries such as India, Pakistan, Bangladesh and Vietnam. This means that any scheme for considering the vulnerable in emergencies needs to recognize the different states of underweight in the so-called 'normal' population.

\section{The potential use of arm circumference in adults}

Fig. 1 shows the relationship between MUAC and BMI in males and females separately. From this relationship it is possible to identify the MUAC values which correspond to the three cut-off points of BMI now used to categorize the grades of underweight. In practice, however, there is considerable variation in MUAC values at each BMI interval and this means that it is difficult to use MUAC as a sensitive discriminator of graded degrees of underweight when conducting cross-sectional surveys. Part of the problem in simply relating MUAC to BMI is that the selective loss of peripheral tissue might vary in different adults and this will be reflected more in a change in MUAC than in the decline in BMI. This may in part explain the scatter in the data. Therefore a new approach to MUAC was explored where this measure was treated as an independent measure of nutritional status. MUAC Z-scores were calculated, i.e. the standard deviations of the distributions of MUAC around the mean values for this international aggregated data set (James et al. 1994). We then assessed the distribution of adults with varying degrees of peripheral depletion as indicated by their MUAC in conjunction with their total body weight expressed as BMI. The value of $-1.0 \mathrm{Z}$-score MUAC was found to be about $228 \mathrm{~mm}$ for men and $219 \mathrm{~mm}$ for women; these values were then rounded off to $230 \mathrm{~mm}$ for men and $220 \mathrm{~mm}$ for women. Table 2 shows that $97 \%$ of adult men and women with a BMI $>18.5$ had a MUAC value above the $-1.0 \mathrm{Z}$-score. In those with extreme underweight, i.e. BMI $<16.0$, practically all had MUAC below the cut-off point. Half the adults between BMI 16.0 and 16.9 were classified as having a low MUAC whereas one quarter of adults with BMI 17.0-18.4 were both underweight and had a low MUAC indicative of substantial wasting of muscular and subcutaneous fat in the arm.

\section{Screening for different degrees of malnutrition in emergencies}

More extreme cut-off points for MUAC are needed under conditions of mass starvation where very limited food supplies mean that only the desperate can be fed. Lower cut-off values were therefore devised on the basis that a 1.0 unit in the $Z$-score distribution of MUAC corresponds in our Third World population groups to $28 \mathrm{~mm}$ for men and $29 \mathrm{~mm}$ for women. A simple set of MUAC cut-off points was thus developed, as shown in Table 
Table 1. The varying prevalence of adult malnutrition in Third World countries*

\begin{tabular}{|c|c|c|c|c|c|}
\hline & \multirow[b]{2}{*}{ Mean BMI } & \multicolumn{4}{|c|}{$\begin{array}{c}\text { Adults in each class of nutritional } \\
\text { status BMI groups ( } \%)\end{array}$} \\
\hline & & $<16.0$ & $16 \cdot 0-16 \cdot 9$ & $17 \cdot 0-18.4$ & $\geqslant 18.5$ \\
\hline \multicolumn{6}{|l|}{ Africa } \\
\hline Congo & $23 \cdot 1$ & $0 \cdot 6$ & $1 \cdot 8$ & $8 \cdot 7$ & 88.9 \\
\hline Ethiopia & $19 \cdot 0$ & $4 \cdot 9$ & $9 \cdot 2$ & $23 \cdot 9$ & $62 \cdot 0$ \\
\hline Ghana & $21 \cdot 6$ & $2 \cdot 8$ & 3.9 & $13 \cdot 3$ & 80.0 \\
\hline Mali & $21 \cdot 1$ & 1.9 & $3 \cdot 2$ & $11 \cdot 2$ & $83 \cdot 7$ \\
\hline Morocco & $23 \cdot 0$ & $0-5$ & $1 \cdot 1$ & $5 \cdot 4$ & 93.0 \\
\hline Senegal & $21 \cdot 7$ & $4 \cdot 3$ & 7.8 & $20 \cdot 9$ & $66 \cdot 0$ \\
\hline Togo & 21.9 & $0 \cdot 3$ & $1 \cdot 2$ & 6.8 & $91 \cdot 7$ \\
\hline Tunisia & $24 \cdot 3$ & $0 \cdot 3$ & 0.6 & 3.0 & $96 \cdot 1$ \\
\hline Zimbabwe & $21 \cdot 3$ & $0 \cdot 7$ & $1 \cdot 1$ & $7 \cdot 2$ & 91.0 \\
\hline \multicolumn{6}{|l|}{ Asia } \\
\hline China & $21 \cdot 8$ & $1 \cdot 0$ & 3.9 & $7 \cdot 4$ & $87 \cdot 7$ \\
\hline India & 19.0 & $10 \cdot 2$ & $12 \cdot 7$ & $25 \cdot 7$ & $51 \cdot 3$ \\
\hline Vietnam & $19 \cdot 0$ & $4 \cdot 1$ & $6 \cdot 5$ & $25 \cdot 6$ & $63 \cdot 7$ \\
\hline \multicolumn{6}{|l|}{ Latin America } \\
\hline Brazil & $23 \cdot 0$ & 0.5 & 0.9 & $4 \cdot 2$ & $94 \cdot 4$ \\
\hline Cuba & $23 \cdot 5$ & 0.6 & $1 \cdot 3$ & $5 \cdot 4$ & $92 \cdot 7$ \\
\hline Peru & $23 \cdot 2$ & 0.2 & 0.2 & $2 \cdot 6$ & $97 \cdot 0$ \\
\hline
\end{tabular}

* Calculated from Shetty \& James (1994) and from World Health Organization (1995).

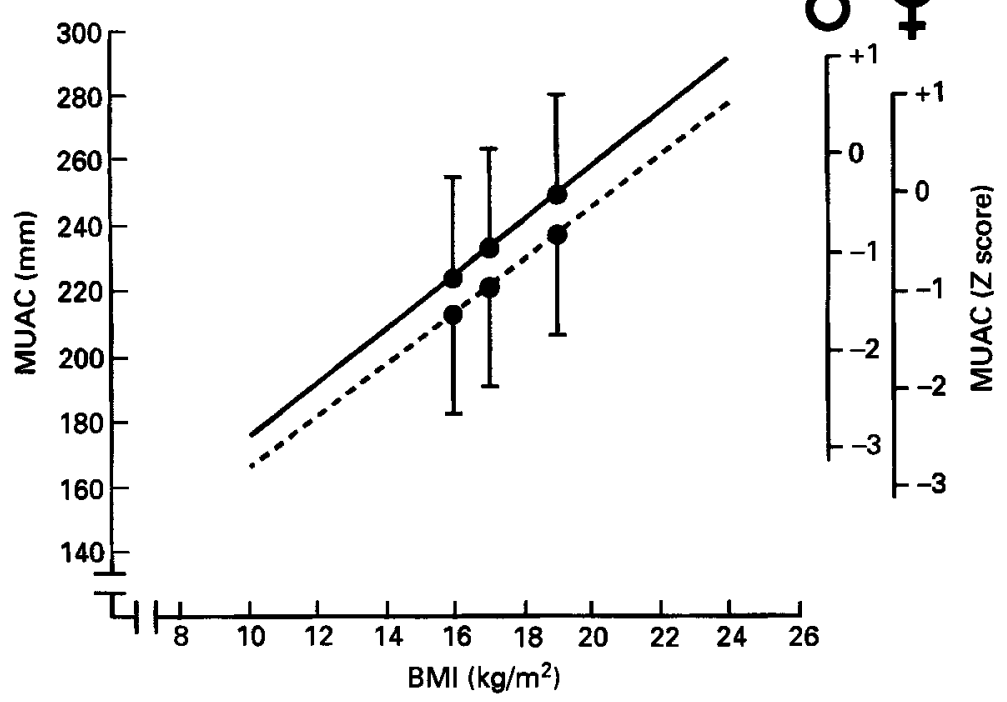

Fig. 1. The relationship between mid upper arm circumference (MUAC) and BMI in 2421 men $(-)$ and 3258 women (--) from Third World populations, the vertical bars indicating standard deviation. The right hand axes show the MUAC Z-scores for men and women separately. (Males: $Y=9.32 a+0.81 b ; r 0.79$. Females: $Y=8 \cdot 83 a+0 \cdot 78 b ; r 0 \cdot 80$.)

3. The corresponding BMI values are also shown. We have limited data from Somalia and India to justify the specification of BMI of 14 and 13 in men and women corresponding to MUAC of 200 and $190 \mathrm{~mm}$ respectively, i.e. in those classified as severely wasted. We have 
Table 2. The percentage distribution of Third World adults in different nutritional categories based on $B M I$ and a rounded value for a mid upper arm circumference $(M U A C)$ of $\pm I S D^{*}$

\begin{tabular}{lrrrrr}
\hline BMI group $\ldots$ & $<16$ & $16-16.9$ & $17-18 \cdot 4$ & $\geqslant 18 \cdot 5$ & Total \\
\hline Men & & & & & \\
MUAC $<23 \cdot 0$ & 90 & 55 & 25 & 3 & 16 \\
MUAC $\geqslant 23 \cdot 0$ & 10 & 45 & 75 & 97 & 84 \\
Total row (\%) & 7 & 7 & 16 & 70 & 100 \\
$n$ & 164 & 163 & 382 & 1712 & 2421 \\
Women & & & & & \\
MUAC $<22 \cdot 0$ & 82 & 52 & 21 & 3 & 12 \\
MUAC $\geqslant 22 \cdot 0$ & 18 & 48 & 79 & 97 & 88 \\
Total row (\%) & 5 & 6 & 15 & 74 & 100 \\
$n$ & 162 & 180 & 493 & 2413 & 3248 \\
\hline
\end{tabular}

* Note that if a combination of a low MUAC and the BMI is used for specifying chronic energy deficiency grades 2 and 3 , then $6 \%$ of men and $5 \%$ of women are affected.

Table 3. A proposed set of mid upper arm circumference (MUAC) values for use when screening adults under famine conditions

\begin{tabular}{|c|c|c|c|c|c|c|}
\hline \multirow{2}{*}{$\begin{array}{l}\text { MUAC } \\
\text { Z-score }\end{array}$} & \multicolumn{2}{|c|}{$\begin{array}{l}\text { MUAC value } \\
\text { (mm) }\end{array}$} & \multirow[b]{2}{*}{ Diagnostic category } & \multicolumn{2}{|c|}{ Approximate corresponding BMI } & \multirow[b]{2}{*}{ Grade of CED } \\
\hline & Men & Women & & Men & Women & \\
\hline$<-1 \cdot 0$ & $<230$ & $<220$ & Undernourished & $<17$ & $<17$ & 3 \\
\hline$<-2 \cdot 0$ & $<200$ & $<190$ & Severe wasting & $<13$ & $<13$ & 4 \\
\hline$<-3 \cdot 0$ & $<170$ & $<160$ & Extreme wasting & $<10$ & $<10$ & 5 \\
\hline
\end{tabular}

CED, chronic energy deficiency.

no direct data as yet to confirm the relationships between the MUAC and BMI values proposed for the extremely wasted category, but a further series of calculations and assessments, set out below, suggests that these values will identify people in desperate need of help.

Survival under extreme conditions: a physiological distinction between men and women As noted by Heymsfield et al. (1984), subcutaneous fat is lost preferentially and this is better displayed by the fat area measurements than as an absolute skinfold thickness since the circumference of the arm contributes substantially to the fat area value. Fig. 2 shows the aggregated data on the relationship between the estimated upper arm area occupied by adipose tissue (with the skin included; AFA) and by muscle (AMA) in our set of Third World adults. Values for each sex are plotted against the measured BMI. The New Guinea values have been excluded because of their unusual muscle:body fat ratios (James $e t$ al. 1988). It is evident that, for both men and women, a BMI of $12-13$ is associated with negligible fat reserves in the arm. Heymsfield et al. (1984) found that the lowest AFA seen in ill and very underweight adults was $2-5 \mathrm{~cm}^{2}$, with a total residual body fat of $0.5-2.0 \mathrm{~kg}$. These values for arm fat correspond to a BMI of 14 in Fig. 2 but Heymsfield's data also suggest that the upper AFA is the first region to be depleted and the last to be repleted. 


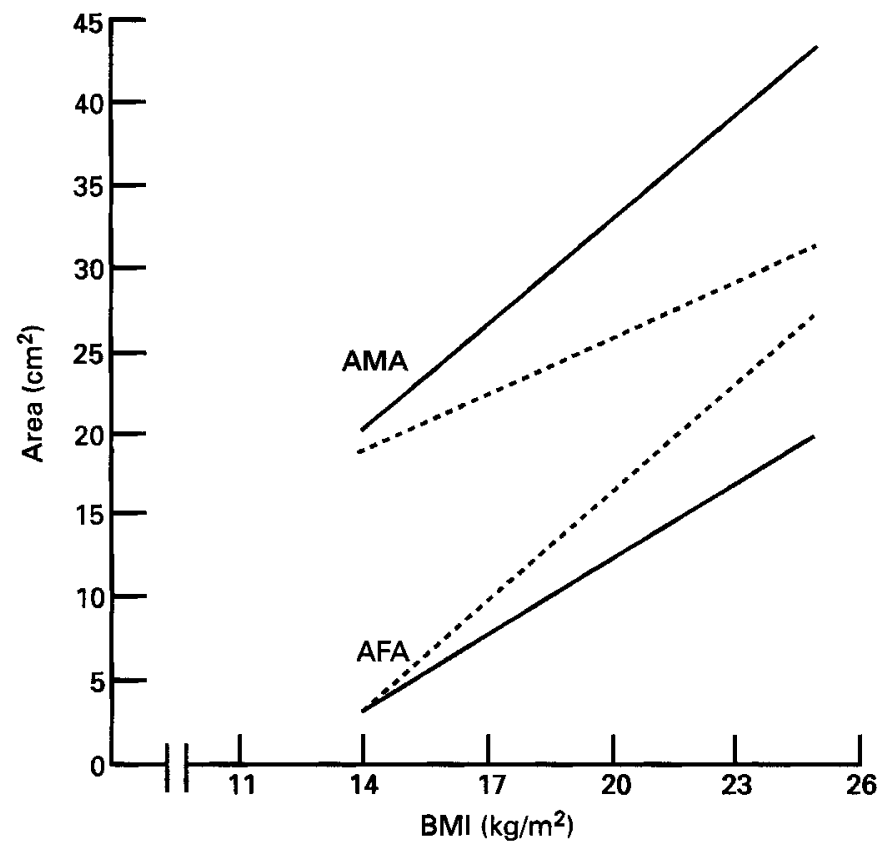

Fig. 2. The relationship between BMI and arm muscle area (AMA) or arm fat area (AFA) in Third World adult males (-) and females (--) of low BMI. The values of AMA are bone-corrected. The data used are the same as for Fig. 1 with the exclusion of the New Guinea population group. (AMA, males: $Y=-9 \cdot 52 a+2 \cdot 05 b ; r 0.59$, females: $Y=2 \cdot 73 a+1 \cdot 13 b ; r 0 \cdot 51$. AFA, males: $Y=-14 \cdot 55 a+1 \cdot 30 b ; r 0 \cdot 49$, females: $Y=-26 \cdot 64 a+2 \cdot 15 b$; $r$ 0.71.)

\section{DISCUSSION}

The remarkably high prevalence rates of adult underweight in Asia naturally raise the question of whether Asians are, for ethnic reasons, constitutionally of a different shape and size from Africans and the mixed cultures of America. Ethnic effects are, however, extremely unlikely because a series of studies on, for example, Indian children of affluent parents has shown that they grow in height and weight at rates corresponding to the North American standards which have been used as reference data on children's growth (Agarwal et al. 1991). Thus, well-fed Asian children, unencumbered by infections, can be expected to emerge from adolescence with body proportions similar to those of healthy Europeans or North Americans. This, in turn, means that the extraordinarily high and previously unrecognized rates of adult underweight and malnutrition in the Indian subcontinent reflect the impact of a truly disadvantageous environment.

The justification for the use of MUAC as a substitute for, or in addition to, the BMI has to be based not only on the epidemiological relationships shown in Fig. 1 but also on physiological and clinical observations linked to the depletion of body reserves. The present results suggest that at lower body weights it becomes important to consider the sexes separately. The men have, in the normal weight range (BMI 18.5-25.0), substantially more muscle but less fat in their arms than women. If these cross-sectional data are considered in dynamic terms, then the different slopes in Fig. 2 acquire considerable significance. Forbes (1987) has shown that when body weight falls, the amount of muscle lost is inversely proportional to the fat content of the body. Thus, overweight adults lose more fat per $\mathrm{kg}$ body weight loss than normal-weight individuals, and women with their constitutionally 
greater fat stores lose less muscle per $\mathrm{kg}$ weight loss than men. These different responses are also readily observed in the seasonal cycling of body weight and body fat in men and women in developing countries (Ferro-Luzzi, 1990).

Clearly Fig. 2 implies that, at a BMI of 13-14, residual fat reserves will be limited. If these BMI are then related to Fig. 1, then designating the MUAC values as $200 \mathrm{~mm}$ for men and $190 \mathrm{~mm}$ for women, i.e. equivalent to -2 sD of the mean MUAC, seems to be justified as a potentially important threshold. Henry (1990) also found men with anorexia nervosa just surviving at this BMI level whereas women seemed to survive at even lower BMI, presumably because they could still call on small amounts of residual body fat.

The sharp decline in the AMA in men at lower weights is striking; this feature may be expected to be accentuated when further wasting occurs and to affect men more than women. Eventually all fat reserves will be lost in both sexes. Extrapolating the line of the men's AMA shows that at a BMI of 10 the men may be expected to enter the AMA zone of $9-11 \mathrm{~cm}^{2}$ which Heymsfield et al. (1984) found to predict death in cachectic cancer patients within 1-2 weeks. The line shown in Fig. 2 for women's AMA may also be expected to curve downwards once fat reserves are exhausted, so a BMI of 10 would also seem to be a reasonable estimate of the corresponding critical level of protein reserves in women. Extending the relationship of BMI to MUAC in Fig. 1 would then seem to justify a choice of $-3 \mathrm{SD}$ of MUAC, i.e. about $170 \mathrm{~mm}$ for men and $160 \mathrm{~mm}$ for women, as likely corresponding values to the BMI values of 11 and 10 respectively.

Further evidence for the vital nature of the depletion of body protein reserves comes from chemical analyses and histological studies on children and adults dying of malnutrition. In children, Picou et al. (1966) demonstrated that normally a quarter of total body protein is in the form of collagen but that in malnutrition there is a selective depletion of non-collagen muscle and general enzymic proteins with death occurring when half the non-collagen protein of the body is lost. Muscle myofibrillar and sarcoplasmic proteins are preferentially sacrificed as protein reserves decline, so this could explain the halving of the men's AMA between a BMI of 24 and 14 (Fig. 2). At extremely low BMI, e.g. 10, a loss of at least two-thirds of the non-collagen proteins from muscle is probable since post-mortem histological studies in malnutrition reveal only residual structural tissues and blood vessels (Montgomery, 1962). Thus the $9-11 \mathrm{~cm}^{2}$ limit observed by Heymsfield et al. (1984) may well constitute the irreducible minimum produced by the persistent collagenous tissue. These physiological and chemical studies are then in keeping with the choice of a MUAC level of $200 \mathrm{~mm}$ and $190 \mathrm{~mm}$ for designating the limit of fat reserves for men and women and the lowest values of 170 and $160 \mathrm{~mm}$ as indicating the precarious state of the vital protein reserves.

\section{Population studies on survival under extreme conditions}

It might be argued that these extremely low levels of MUAC and BMI are incompatible with life, but reports from African emergencies indicate that adults with BMI of below 10 are sometimes found alive (R. Bahtia, United Nations High Commission for Refugees, personal communication). These values are indeed considered to be barely compatible with life when based on data from Western patients with anorexia nervosa (Henry, 1990), but three issues may explain the continued survival of adults with extremely low BMI in developing countries.

The first is that some reports relate to tribal groups where a body shape with very long thin limbs leads to underestimates of the BMI appropriate to their weight and height. Thus, the normal BMI may need adjusting upward by measuring the sitting height and then correcting the BMI (Norgan, 1994). This, however, makes only a modest contribution to explaining the continued survival of adults with a true BMI in the 10-12 range. 
The second possible explanation is that acute weight loss, e.g. in patients with anorexia nervosa or hunger strikers, imposes a much more acute stress on the body, with greater catabolic losses of protein, than long-standing undernutrition where children and adolescents have always been thin and have grown up under conditions of very limited nutrient intakes. Shetty and his colleagues consider that this has an effect on differential organ growth (Shetty, 1993) and there may also be some reprogramming of metabolism. Practical support for this conclusion comes from the contrast between information on deaths under seige conditions and our data on Somalian military recruits and women in the poorest rural areas of India who have BMI in the 13-14 region. Accounts of death during the Leningrad siege showed that weight losses amounting to only $25 \%$ led to adults becoming extremely unwell and lethargic (Keys et al. 1950). Under idealized conditions of semi-starvation in previously healthy volunteers without chronic infection or parasitism, Keys et al. (1950) also observed a fall in BMI from 21.8 to 16.5 . In this later state of approximate energy balance after rapid weight loss over a 6 -month period, the subjects were extremely inactive and probably much less active than the Somalian soldiers or Indian women who, although subject to recurrent infections, managed to maintain some semblance of work. Finally, differences in the metabolic responses to total starvation, e.g. in hunger strikers and in those who semi-starve, are to be expected because in total fasting preferential use of protein stores occurs to provide the glucose needed for brain metabolism. Thus, refugees able to scavenge some food will limit their protein wasting.

These simple comparisons are, in practice, complicated by the frequency of infection in both clinical and disaster settings; infection has a powerful effect in inducing selective and severe depletion of peripheral protein stores. Thus, it is the infection-induced selective catabolic loss of protein that explains the extreme illness of overweight infected Western patients who lose muscle and reduce their AMA whilst still retaining substantial amounts of total body and subcutaneous fat. Similarly, the impact of crowding and poor sanitation with cross infection accentuates the problems in refugee camps. In these circumstances, arm measurements and particularly muscle values are likely to be more valuable indices of risk than the BMI values alone (Bistrian, 1984).

\section{Implications for supplementary feeding}

These data allow a simple scheme to be devised for assessing populations in need of screening and those individuals who specifically need supplementary feeding. MUAC may also be used to prioritize the needs of different groups (Table 3). If many relief agencies are confronted with a substantial number of scattered groups who need help, then assessing a random sample of 150-300 or more adults from each group for their MUAC will help to identify those groups with a substantial proportion of adults in need of sustained rehabilitation (Lwanga \& Lemeshow, 1991). Thus, the finding of an average MUAC of $220-230 \mathrm{~mm}$ in the adults will signify that nearly a fifth of the adult population is likely to have MUAC values $1 \mathrm{SD}$ unit or more below this mean, i.e. below $200 \mathrm{~mm}$ and $190 \mathrm{~mm}$ for men and women respectively. At these MUAC values the arm fat stores are exhausted. The individual is then moving into a danger zone classified by us as 'severe wasting'. We suggest that food supplements are required urgently for these individuals. Alternatively, the decision may be taken to feed the whole group for operational reasons.

Current evidence emerging from the war zones of Africa suggests that even these criteria for selecting adults for screening may be too generous when food supplies are very limited. A MUAC value corresponding to -3 SD of the usual Third World values, i.e. $<170 \mathrm{~mm}$ for men and $<150 \mathrm{~mm}$ for women, will signify an extreme form of wasting with marked atrophy of protein as well as of fat stores. Under these circumstances it is very likely that cardiac muscle as well as skeletal muscle will have shared in the general atrophy. These 
adults will then be in need of rather more sophisticated care with a low $\mathrm{Na}$ intake, a wellbalanced mineral intake and only modest amounts of dietary energy and protein until their over-hydrated and metabolically deranged tissues can cope with greater inputs of food (Golden, 1995). Without these special measures acute deaths from rapid cardiac failure or from diarrhoea induced by poorly digested food are as likely in adults as in children. This problem was well recognized in adults as a complication of therapy in Auschwitz and Belsen.

The background information for these analyses was obtained with the financial support of DGXII of EU, within the STD , STD $_{2}$ and $\mathrm{STD}_{3}$ Framework Programmes and by the Scottish Office Agriculture and Fisheries Department.

\section{REFERENCES}

Agarwal, K. N., Agarwal, D. K., Benakappa, D. G., Gupter, S. M., Kanduja, P. C., Khatua, S. P., Ramachandran, K., Udani, P. M. \& Gopalan, C. (1991). Growth Performance of Affluent Indian Children (Under Fives). Nutrition Foundation of India. Scientific Report no. 11.

Bistrian, B. R. (1984). Nutritional assessment of the hospitalized patient: a practical approach. In Nutritional Assessment, pp. 183-205 [R. A. Wright and S. Heymsfield, editors]. Oxford: Blackwell Scientific Publications.

Ferro-Luzzi, A. (1990). Seasonality studies in three developing countries: introduction and background. European Journal of Clinical Nutrition 44, 3-7.

Ferro-Luzzi, A., Sette, S., Franklin, M. \& James, W. P. T. (1992). A simplified approach of assessing adult chronic energy deficiency. European Journal of Clinical Nutrition 46, 173-186.

Forbes, G. B. (1987). Lean body mass-body fat interrelationships in humans. Nutrition Reviews 45, $225-231$.

Golden, M. H. N. (1995). Severe malnutrition. In The Oxford Textbook of Medicine, Vol 1, 3rd Ed, pp. 1278-1296. [D. J. Weatherall, J. G. G. Ledingham and D. A. Warrell, editors] Oxford: Oxford University Press.

Henry, C. J. K. (1990). Body mass index and the limits of human survival. European Journal of Clinical Nutrition 44, 329-335.

Heymsfield, S. B., McManus, C. B. III, Seitz, S. B., Nixon, D. W. \& Smith Andrews, J. (1984). Anthropometric assessment of adult protein-energy malnutrition. In Nutritional Assessment, pp. 27-82 [R. A. Wright and S. Heymsfield, editors]. Oxford: Blackwell Scientific Publications, Inc.

James, W. P. T., Ferro-Luzzi, A. \& Waterlow, J. C. (1988). Definition of chronic energy deficiency in adults. Report of a Working Party of the International Dietary Energy Consultative Group. European Journal of Clinical Nutrition 42, 969-981.

James, W. P. T., Mascie-Taylor, C. G. N., Norgan, N. G., Bistrian, B. R., Shetty, P. S. \& Ferro-Luzzi, A. (1994). The value of arm circumference measurements in assessing chronic energy deficiency in Third World adults. European Journal of Clinical Nutrition 48, 883-894.

Keys, A., Brozek, J., Henschel, A., Michelson, O. \& Taylor, H. L. (1950). The Biology of Human Starvation. Minneapolis: University of Minnesota Press.

Lwanga, S. K. \& Lemeshow, S. (1991). Sample Size Determination in Health Studies. A Practical Manual. Geneva: World Health Organization.

Montgomery, R. D. (1962). Muscle morphology in infantile malnutrition. Journal of Clinical Pathology 13, $511-519$.

Norgan, N. G. (1994). Relative sitting height and the interpretation of the body mass index. Annals of Human Biology 21, 79-82.

Picou, D., Halliday, D. \& Garrow, J. S. (1966). Total body protein, collagen and non-collagen protein in infantile protein malnutrition. Clinical Science 30, 345-351.

Shetty, P. S. (1993). Chronic undernutrition and metabolic adaptation. Proceedings of the Nutrition Society 52 , 267-284.

Shetty, P. S. \& James, W. P. T. (1994). Body Mass Index: A Measure of Chronic Energy Deficiency in Adults. Rome: Food and Agriculture Organization.

Weiner, J. S. \& Lourie, J. A. (1981). Practical Human Biology. London: Academic Press.

World Health Organization (1995). Physical Status: The Use and Interpretation of Anthropometry. Chapter 5: Infants and Children. Technical Report Series 854. Geneva: World Health Organization. 